\title{
LAS CÁTEDRAS DE LENGUAS INDÍGENAS EN LA UNIVERSIDAD \\ DEL REINO DE GUATEMALA, SIGLOS XVII-XIX
}

\author{
AdRIANa Álvarez SÁnchez \\ Facultad de Filosofía y Letras, \\ Universidad Nacional Autónoma de México
}

\begin{abstract}
ReSumen: Una de las características de las poblaciones americanas fue la diversidad linguiística. Cuando la Corona española hubo conquistado estos territorios, el soberano y sus consejeros establecieron la manera en que se debía evangelizar a los indígenas y así extender la cristiandad. Entre las acciones para llevar a cabo ese objetivo se encuentra la creación de cátedras universitarias donde los aspirantes a sacerdotes deberían aprender, al menos en teoría, las denominadas lenguas generales. En la Real Universidad de San Carlos de Guatemala, fundada en 1676, existieron dos cátedras de lenguas, una de pipil y otra de cakchiquel: la primera únicamente fue leída durante los primeros años, y aunque la segunda sobreviviría hasta el siglo $\mathrm{xIX}$, la falta de estudiantes fue constante. Esa permanencia estuvo relacionada, no con un interés filológico y evangelizador, sino con la búsqueda por parte de sus catedráticos del ascenso de su carrera administrativa dentro del clero.
\end{abstract}

Palabras clave: historia, Guatemala, Universidad, lenguas, cátedras.

AвsтRACT: One of the characteristics of the before the Conquest American population was linguistic diversity. When the Spanish Crown had finished this process, the sovereign and his counselors set the way they should evangelize the Indians and extend Christianity. Among the actions to accomplish this goal was the creation of university chairs where aspiring priests could learn, at least in theory, general languages. In the Real Universidad de San Carlos de Guatemala (founded 1676) there were two languages chairs, one of Pipil and other Cakchiquel: the first one only was read during the early years, and although the second would survive until the nineteenth century, the lack of students was constant. That stay was associated not with a philological and evangelical interest, but with their professors pursuing his administrative career in the clergy.

KEYwoRDs: History, Guatemala, University, languages, chairs.

RECEPCIÓN: 27 de agosto de 2014.

ACEPTACIÓN: 15 de octubre de 2014. 


\title{
LAS CÁTEDRAS DE LENGUAS INDÍGENAS EN LA UNIVERSIDAD DEL REINO DE GUATEMALA, SIGLOS XVII-XIX
}

\author{
Adriana Álvarez SÁnChez \\ Facultad de Filosofía y Letras, \\ Universidad Nacional Autónoma de México
}

Las universidades fueron instituciones que sirvieron a la formación de una burocracia profesional en quien se delegaba la administración de los territorios y los pobladores súbditos de la Corona española en Europa, Asia, África y América. ${ }^{1}$ El primer siglo de vida colonial evidenció las diferencias que había entre las culturas, la historia y las lenguas de los nativos y las de los españoles. Las experiencias previas para resolver esas diferencias, incluidos sus resultados, fueron las principales estrategias que el soberano y sus consejos reales utilizaron para gobernar tierras tan lejanas como Las Indias. La política linguiística aplicada en el Reino de Guatemala fue semejante a la que se impuso en otros territorios del virreinato de la Nueva España, al que pertenecía: ${ }^{2}$ se alternaron la castellanización y el uso de las lenguas indias para la evangelización, el comercio y el control de la población. Dichas estrategias se implementaron desde diversas instituciones, entre ellas la Universidad. Este será el tema a tratar en el presente artículo, con base en los documentos del acervo institucional.

La fundación de la Real Universidad de San Carlos de Guatemala tuvo lugar en 1676. Sin embargo, los antecedentes de su solicitud se remontan a varias décadas atrás. Distintos personajes de la vida pública de la ciudad elevaron en diferentes momentos sus peticiones al rey para que éste aprobara la existencia de una universidad en aquella ciudad, donde la población era mayoritariamente indígena y mestiza. A principios del siglo xvil se calcula que había 720 vecinos y unos 7,000 residentes en Santiago de los Caballeros de Guatemala. ${ }^{3}$ A pesar de que la diversi-

\footnotetext{
${ }^{1}$ De acuerdo con Perry Anderson, el Estado moderno buscó formar una burocracia profesional. Sin embargo, los universitarios no fueron los únicos que integraban ese cuerpo administrativo, también encontramos militares o escribanos, quienes se formaban empíricamente, pero que, en el mundo hispánico, tenían que ser certificados por la Corona. Véase Perry Anderson, 1979, El Estado Absolutista, trad. de Santos Juliá. México: Siglo XXI (Historia).

${ }^{2}$ Cabe aclarar que el Reino contaba con Audiencia propia, que dependía directamente del Consejo de Indias, aunque algunas de las instituciones establecidas en México tenían jurisdicción sobre tierras centroamericanas, como la Inquisición, misma que extendía su territorialidad jurisdiccional no sólo al Reino de Guatemala, sino también a las Filipinas.

${ }^{3}$ David Jickling, 1985, "The vecinos of Santiago de Guatemala in 1604”, Estudios del Reino de Guatemala. Homenaje al profesor S. D. Markman, pp. 77-100. Sevilla: Duke University, Escuela de Estudios Hispanoamericanos, Consejo Superior de Investigaciones Científicas. George Lovell y Christopher Lutz
} 
dad linguiística fue una de las principales características de la población americana $\mathrm{y}$, en particular, de la del reino guatemalteco, la primera vez que las lenguas indias fueron mencionadas en el contexto de la creación de la Universidad fue en 1659, año en que el obispo fray Payo Enríquez de Rivera redactó un extenso informe sobre la importancia de enseñar las lenguas dentro de la Universidad. El obispo formaba parte de una Junta, nombrada por el rey, para informar al monarca sobre la posibilidad de crear un Estudio General en la capital de Guatemala. Pero fray Payo consideró conveniente realizar un documento independiente al de la Junta. ${ }^{4}$ A lo largo de 68 puntos, el prelado señaló la importancia de que en la ciudad se fundara una universidad: la falta de estudios en facultades como medicina y ambos derechos (civil y canónico). También defendió el proyecto universitario real y no el que hasta entonces había prevalecido: jesuitas y dominicos habían estado y estarían en pugna, durante décadas, por la primacía de los estudios que ofrecían en sus conventos, limitados a la enseñanza de las artes (filosofía) y la teología. Así, el prelado hizo explícita su postura ante la oportunidad de que en Guatemala se fundase un Estudio General bajo el patronato del rey. En el punto octavo de su escrito, señaló lo siguiente acerca de la necesidad de enseñar a los clérigos la lengua de su grey:

A estas razones generales, y a las que singularmente se ofrecen en esta provincia para que necesite de Universidad más que otras, se llega, Señor, la necesidad precisa que tiene de una cátedra de lenguas, y de maestros que, con perpetuidad, las enseñen, y de discípulos que las aprendan. Este estudio, Señor, y profesión se ha de considerar, en cuanto a la utilidad, al igual de la utilidad de que haya ministros idóneos para la enseñanza, doctrina y administración de tantos y tan innumerables pueblos de indios, que no saben ni entienden más lengua que la suya, y las suyas son muchas y muy diferentes, y todas de suma dificultad. Esta facultad, Señor, no tiene quien la enseñe, ni hay en esta provincia, ni en las vecinas donde se aprenda; con que, en el estado presente, no se halla como acaso un ministro lengua, y mucho menos un examinador que pueda averiguar si la sabe el que se expone $[\ldots] .^{5}$

\footnotetext{
han señalado que para 1620 toda Centroamérica albergaba un total de 2800 vecinos españoles, refiriéndose a las cabezas de familia, y no al número de habitantes. Si se extrapola esa cifra total y se compara con el dato de 1604 , es posible decir que casi un $26 \%$ de los vecinos residía en la capital de la Capitanía General de Guatemala (Demografía e Imperio. Guía para la historia de la población de la América Central española, 1500-1821, 2000, p. 17. Guatemala: Editorial Universitaria USAC y Plumsock Mesoamerican Studies).

4 "Parecer del ilustrísimo señor don fray Payo Enríquez de Ribera, obispo de Guatemala”, 17 de octubre de 1659, en AGI, Audiencia de Guatemala, 373, ff. 88-116v. El documento fue editado por Juan Rodríguez Cabal, 1965, "Don fray Payo de Ribera y la Universidad de Guatemala”, en Missionalia Hispánica, año XII (66): 17-54. Madrid: Consejo Superior de Investigaciones Científicas. El mismo autor publicó el documento de nuevo en 1966, en Anales de la Sociedad de Geografía e Historia de Guatemala, t. XXXIX (1-4): 36-75. Guatemala: Sociedad de Geografía e Historia.

${ }^{5}$ AGI, Audiencia de Guatemala, 373, f. 93v. Un estudio más completo acerca del proyecto de universidad propuesto por fray Payo puede verse en Adriana Álvarez Sánchez, Patronazgo y educación. Los proyectos y la fundación de la Real Universidad de San Carlos de Guatemala. 1619-1687. México: Universidad Nacional Autónoma de México, Facultad de Filosofía y Letras, en prensa.
} 
Llama la atención que, a pesar de la presencia de frailes "lengua" en el reino, fray Payo afirmase que no había clérigos con estos conocimientos y que los obispos debían hacer nombramientos en los beneficios y curatos "a cualesquiera que dice que es lengua, aunque le falte todo lo demás que necesita un cabal y decente ministro, por no haber en qué escoger". El ministro ponía sobre la mesa uno de los problemas que la Corona había buscado resolver a través de la creación de cátedras de lenguas dentro de las universidades.

En efecto, desde 1580, el monarca había ordenado crear esas sillas, convirtiendo en obligatorio el paso y aprobación de las mismas por parte de quienes aspiraran al sacerdocio. A lo largo de la época colonial, el soberano y su Consejo de Indias establecieron una serie de mecanismos para distribuir los cargos de la administración y, en este caso, implantar la obligatoriedad de probar saber la lengua - certificada por la Universidad - parecía la solución. No obstante, en México, estas cátedras no se crearían sino hasta $1640 .^{6}$

\section{La fundación de la Universidad y las cátedras de lenguas indias}

En 1676, la ciudad de Guatemala recibió la cédula real por la que se creaba la Universidad Real. ${ }^{7}$ Después de varias décadas y pugnas entre grupos políticos, el soberano había decidido atender la petición de obispos, regidores del Ayuntamiento, órdenes religiosas y otras autoridades civiles, fundando un Estudio General que llevaría por nombre Real Universidad de San Carlos de Guatemala.

Las facultades con las que se fundó la Universidad fueron las que tradicionalmente habían existido en instituciones creadas en el siglo xvı: Artes, Teología, Cánones, Leyes y Medicina. Además, existían diversas cátedras sin facultad o sueltas que formaban parte de los estudios de la época, como la de Retórica, la de Gramática o las de Lenguas "Generales". En el caso de San Carlos, la enseñanza de las lenguas había sido un argumento de las peticiones para su fundación.

A la opinión de fray Payo Enríquez de Rivera seguiría, en 1664, una cédula real dirigida a la Audiencia en la que el monarca hace referencia a la carta enviada por el prelado en noviembre del año anterior. El soberano disponía la forzosa examinación de los frailes que pretendieran optar a un curato por "cathedrático que disputa para esta enseñança sin que se puedan ni escusen con decir que cum-

\footnotetext{
${ }^{6}$ Sobre esta cátedra, véase Adriana Álvarez Sánchez, 2009, "La cátedra universitaria de lenguas indígenas en México. Siglos xVI y xvI”, De la barbarie al orgullo nacional. Indígenas, exclusión y conciencia histórica, siglos XVI al XIX, pp. 153-187, Miguel Soto Estrada y Mónica Hidalgo Pego (coords.). México: Universidad Nacional Autónoma de México.

${ }^{7}$ La cédula real data del 31 de enero de 1676, y arribó a Guatemala en octubre de ese mismo año. La original se encuentra en el AGCA, A1.3, leg. 1882, exp. 12235; AGI, Audiencia de Guatemala, ff. 271-276v. Fue publicada en 1976, John Tate Lanning, Reales cédulas de la Real y Pontificia Universidad de San Carlos de Guatemala, $2^{\text {a }}$ edición, pp. 22-30. Guatemala: Editorial Universitaria (Tricentenario de la Universidad de San Carlos de Guatemala). Sobre la llegada de la cédula véase Francisco Ximénez, 1993, Historia de la Provincia de San Vicente de Chiapa y Guatemala. Chiapas: Consejo Estatal para la Cultura y las Artes, t. II, I. IV, cap. 77, p. 204.
} 
plen con tener otros religiosos que saven la lengua y exercen”. Además, la cédula ordenaba que los ministros enviasen informe acerca de la necesidad de contar con una Universidad para enseñar las lenguas indígenas. Finalmente, cuando el rey aprobó la fundación de la Universidad, aceptó a la vez la propuesta de que existieran dos cátedras de lenguas, las más generales del reino. ${ }^{8}$

La decisión de elegir qué lenguas se enseñarían quedó en manos de la Junta de Erección, conformada por autoridades reales, quienes consideraron que las lenguas que debían enseñarse eran la mexicana o pipil y el cakchiquel o kaqchikel. Ambas lenguas representaban a grupos linguísticos concretos; ${ }^{9}$ el pipil contaba con un sistema de escritura, siendo además la lengua de un grupo privilegiado que tenía la capacidad de emitir documentación legal ante las autoridades locales; el cakchiquel, por su parte, era la lengua de la población más cercana a la capital del reino, es decir, al centro de poder. De ahí que tanto una como otra lengua fueran reconocidas como las "principales" o "generales".

Una vez iniciado el proceso de organización de la Universidad, al llevar a cabo los concursos de oposición para las cátedras, sólo la de cakchiquel quedó cubierta. El fraile dominico José Ángel Cenollo fue quien obtuvo, en 1678, el cargo en calidad de propietario, es decir, de manera vitalicia. Sin embargo, los conflictos que se dieron a raíz del nombramiento de los catedráticos de teología, que mantenían viva la rivalidad entre frailes y clero secular, llevaron al soberano a cambiar todos los nombramientos a interinos. ${ }^{10}$ Esta decisión habría de retrasar aún más el inicio de las actividades universitarias, pues dos de los catedráticos electos - el de leyes y el de cánones - renunciaron a sus cargos, mientras que el médico, que había concursado desde México, nunca llegó a Guatemala. La nueva condición del nombramiento fue determinante en la decisión de los catedráticos que prefirieron buscar, por otros caminos, el prestigio social y el ascenso burocrático que podían iniciar en la Universidad leyendo una cátedra.

\footnotetext{
${ }^{8}$ La carta del obispo está fechada en 16 de noviembre de 1663 . La cédula real es del 23 de septiembre de 1664. AGI, Audiencia de Guatemala, 373, ff. 119-121.

${ }^{9}$ Recientemente Laura Matthew y Sergio Romero, con base en el análisis comparativo de documentos coloniales de distintas tipologías, postularon la existencia de un pipil guatemalteco, con rasgos específicos ("El pipil en la Guatemala colonial: unas propuestas", ponencia leída en el XII Congreso Centroamericano de Historia, San Salvador, El Salvador, del 14 al 18 de julio de 2014).

${ }^{10}$ Los conflictos se dieron desde el inicio de los concurso de oposición en 1677, cuando el entonces chantre de la catedral, José de Baños y Sotomayor, aspirante a prima de Teología, impugnó la participación de los frailes dominicos en los concursos. Los nombramientos finales en favor de los frailes, tanto en la cátedra de cakchiquel, como en Artes y Teología, desataron la ira del chantre, quien interpuso una queja ante la Junta de Erección, a la cual se unió Esteban de Cuña Moreira, quien concursó en vísperas de Teología. Además el obispo y el nuevo presidente de la Audiencia también presentaron quejas, el primero por la manera en que se estaban realizando los concursos, y el segundo reclamando su derecho a votar en la elección de los lectores: en diciembre de 1678, él ya se encontraba en la jurisdicción del Reino y la Junta no esperó a su llegada, sino que eligió a los catedráticos en dicho mes. El proceso ha sido estudiado detalladamente en Adriana Álvarez Sánchez, 2007, "La Real Universidad de San Carlos de Guatemala, 1676-1790", tese de doutoramento en Historia. Santiago de Compostela: Universidad de Santiago de Compostela, Facultade de Xeografía e Historia.
} 
A la cátedra de Lengua Mexicana no se presentó ningún aspirante. Ésta no se ocuparía sino hasta 1686, año en que el primer rector designó al bachiller y presbítero Lorenzo González de Maeda, como lector interino. Dos años después, el catedrático opositó y obtuvo la cátedra en propiedad. ${ }^{11}$

En un inicio, las cátedras de lenguas fueron ocupadas por frailes. Es poco lo que sabemos de los cursantes debido a las lagunas documentales en los registros de la institución y quizá también a que no tuvieron estudiantes. Las noticias sobre las cátedras se pierden desde los años ochenta del siglo xvI y hasta 1709, año en que se registra información sobre la de lengua mexicana. Se trata de una petición del bachiller Pedro de Bárcena, quien solicitó al rector leer la cátedra de "extraordinario", es decir, interinamente, debido a la muerte de González de Maeda. La solicitud obedecía a que se habían fijado edictos para la oposición de la cátedra, pero no hubo concurrencia de concursantes. ${ }^{12}$ De esta manera, el aspirante a lector ganaría méritos en la lectura de la cátedra para cuando el Claustro decidiera convocar nuevamente a concurso la silla. No obstante que la petición llegó al Claustro pleno el 10 de enero de 1709, se desconoce la decisión de éste. En el resto de la documentación universitaria no encontramos indicios de que Bárcena haya logrado su objetivo, incluso no es posible asegurar que se le permitiera leer la cátedra. Ésa es la última noticia sobre la enseñanza de la lengua mexicana: en ningún otro documento se hace referencia a ella, ni a su catedrático. La serie de expedientes o autos de oposición a cátedras no registra concurso alguno en la cátedra, por lo que quizás, ante la falta de lectores y probablemente de cursantes, la lectura quedara suspendida temporalmente.

En el caso de la cátedra de Lengua Cakchiquel el desarrollo de su lectura también presenta lagunas documentales, aunque en este caso se conservan varios concursos de oposición y referencias en los libros de claustros que permiten reconstruir su desarrollo hasta los años veinte del siglo xIX.

\section{La cátedra de cakchiquel en el siglo xvIII}

Durante las primeras dos décadas de vida universitaria, la cátedra fue regida por el dominico José Ángel Cenollo. Una vez que éste murió, en 1700, las noticias sobre la

\footnotetext{
${ }^{11}$ En el AGCA no se conserva el expediente del concurso, pero en AGI, Audiencia de Guatemala, 154, se encuentra copia de los concursos de tres cátedras: vísperas de Teología, prima de Artes y Lengua mexicana. Por otra parte, cabe aclarar que en esta época en las cátedras se impartín lecciones, por lo que la acción realizada por los catedráticos era la de "leer". Había lecciones ordinarias que eran dictadas en las cátedras y lecciones extraordinarias o de extraordinario" que eran lecciones que los pasantes u opositores a cátedra ofrecían en la Universidad, previa aprobación del rector. Acerca de ello y de la manera en que los conocimientos eran transmitidos véase Clara Inés Ramírez González y Mónica Hidalgo Pego, 2001, “Los saberes universitarios", La Universidad de México. Un recorrido histórico de la época colonial al presente, pp. 70-86, Renate Marsiske (coord.). México, Universidad Nacional Autónoma de México, Centro de Estudios Superiores Universitarios y Plaza y Valdés Editores.

${ }^{12}$ AGCA, A1.3, leg. 1899, exp., 12475, f. 1.
} 
silla son nulas, y será hasta 1730 cuando se convoque a la propiedad de la cátedra. Es posible que el Claustro decidiera reactivar al menos una de las sillas de lengua en razón de las constantes quejas de que los sacerdotes desconocían las lenguas de sus beneficios. Al concurso se presentaron dos aspirantes: un fraile dominico y bachiller en artes, fray Agustín Rodríguez, y un clérigo presbítero, el bachiller Nicolás Cifuentes. Fue este segundo el que, con los seis votos de la Junta, obtuvo el cargo en propiedad, como lo registra el concurso de oposición. ${ }^{13}$

A la muerte del bachiller Cifuentes se convocó a un nuevo concurso en 1751 , al que únicamente se presentó el franciscano Juan de Almeida, quien obtuvo cinco votos de la Junta. ${ }^{14}$ El procurador general franciscano aprovechó para solicitar al rey que le concediera licencia para que la Orden de San Francisco tuviera la exclusividad en la lectura de lengua cakchiquel. El soberano, en 1756, respondió negativamente, argumentando que sólo se conseguiría retraer "[...] de asistir los estudiantes a su lectura, como destituidos del premio que podían esperar en el ascenso a su regencia, y por consiguiente faltarían los sujetos capaces de la citada lengua, como prácticamente se ha visto en la citada ocasión de no aver ocurrido mas opositor que el expresado religioso [...]", refiriéndose al concurso que ganó Almeida. ${ }^{15}$

El Claustro obedeció lo ordenado por el rey, es decir, mantener la cátedra de Lengua Cakchiquel con la misma categoría. En realidad el rey estaba defendiendo su derecho como patrono de la Universidad. ${ }^{16}$ Los franciscanos ya contaban con dos cátedras exclusivas: Teología y Artes, y permitir que regentaran otra era abrir un espacio más a la Orden en la Universidad. Por otra parte, la cátedra de lenguas representaba en sí misma un espacio de poder, ya que en teoría era la silla desde la que se certificaría a quienes aspiraran al sacerdocio, además de que en la carrera de los propios catedráticos la lectura de estas cátedras también representó una oportunidad de ascender como ministros de la monarquía.

El Claustro no volverá a tratar nada relacionado con las cátedras de lenguas hasta 1762, año en que se llevó a cabo el concurso de oposición debido a la muerte de su propietario, Juan de Almeida. Esta vez sólo se presentó un fraile, el también franciscano Ildefonso Joseph Flores. El Claustro pleno trató sobre el

13 AGCA, A1.3, leg. 1900, exp. 12490 y leg. 1890, exp. 12338, ff. 28-28v.

${ }^{14}$ AGCA, A1.3, leg. 1901, exp. 12509.

15 AGCA, A1.3, leg. 1882, exp. 12236, ff. 128-129. También en John Tate Lanning, op. cit.

16 La defensa del patronato real de las universidades hispanoamericanas frente a las órdenes religiosas fue constante a lo largo del periodo colonial. Son varios los autores que han estudiado la relación de la universitas con los frailes, entre ellos Clara Inés Ramírez González, 2001, Grupos de poder clerical en las universidades hispánicas. Los regulares en Salamanca y México durante el siglo xVI. México: Universidad Nacional Autónoma de México y Centro de Estudios Superiores Universitarios, 2 vols. (La Real Universidad de México. Estudios y Textos XII y XIII), y Enrique González González, 2010, "Por una historia de las universidades hispánicas en el Nuevo Mundo (siglos XVI-XVIII)", Revista Iberoamericana de Educación Superior (RIES), 1, (1): 77-101. México: Instituto de Investigaciones sobre la Universidad y la Educación, Universidad Nacional Autónoma de México, disponible en <http:// ries.universia.net.mx/index.php/ries/article/view/29> (consulta: 15 de noviembre de 2014). 
asunto, cuestionando la existencia de la cátedra, y aunque los doctores declararon por válida la presentación al concurso del fraile, sugirieron adjudicar la cátedra de manera interina mientras se consultaba al patrono de la Universidad a fin de suprimirla y utilizar el salario para crear una de cirugía. Los argumentos para tal propuesta estaban relacionados, por un lado, con la política de castellanización de la población impulsada por la Corona, y por otro, con la mínima o nula eficacia de enseñar cakchiquel en un Reino en el que la diversidad linguiística era endémica. Por tanto, el Claustro se pronunció a favor de orden real de enseñar

[...] a los yndios la lengua castellana, sobre que han fundado escuelas por los curas seculares que han entrado en las doctrinas de los regulares por punto general en estas yndios, y porque siendo muchas las lenguas o idiomas de que se vean en los pueblos de este arzobispado y obispado sufragáneo, diferentes en el todo de la lengua kachiquel que es la única que se provee, parece no se ocurre a la nececidad de [el]la realmente $[\ldots] .{ }^{17}$

El Claustro también señaló que no se realizaba la certificación del catedrático de lengua para propagar la religión y que se tenía que acudir a aprender los idiomas "con el comercio de los mismos indios", es decir, a través de la comunicación cotidiana con ellos. Se añadió que era necesario tener presente la Ley 49, título 22 del Libro primero de la Recopilación de Las Indias en la que se ordenaba que para catedrático de "idiomas" en la Real Universidad de México, sólo se aceptara a clérigos y jesuitas. ${ }^{18}$ Se aludía a este último argumento en razón de que el Claustro estaba dominado por el clero secular, ${ }^{19}$ es decir, por el grupo al que afectaba directamente la obligatoriedad de aprobar la cátedra de lenguas como requisito para el sacerdocio. En cuanto a los padres jesuitas, ni en México ni en Guatemala tuvieron cabida como catedráticos de lenguas dentro de las universidades reales. Fuertes opositores a la fundación de San Carlos, en Guatemala se limitaron a la enseñanza de las primeras letras, artes y teología.

Debido a la discusión sobre la desaparición de la cátedra de Cakchiquel, la adjudicación en favor de fray Ildefonso Joseph Flores no procedió sino nueve meses después. El 23 de diciembre de 1662 tomó posesión de la propiedad de la cátedra. ${ }^{20}$ Flores leería durante una década. En mayo de 1772 presentó su renuncia, que fue aceptada por el Claustro de consiliarios. Por ello se ordenó convocar a un nuevo concurso. Sin embargo, el nueve de mayo de ese mismo año, el Claustro volvió a hacer explícita su opinión sobre la cátedra, pero acordó que ésta se

${ }^{17}$ AGCA, A1.3, leg. 1890, exp. 12338, f. 29-29v.

18 Ibid., ff. 29v-32.

19 El clero de la Iglesia católica se divide en clero regular y clero secular: el primero cumple con las reglas de su orden religiosa (los frailes) y el segundo obedece directamente lo ordenado por la jerarquía eclesiástica, cuyo máximo representante es el Papa. Debido a que los frailes contaban con autoridades propias, los conflictos entre éstos y el clero secular fueron constantes a lo largo del periodo colonial.

${ }^{20}$ AGCA, A1.3, leg. 1890, exp. 12338, ff. 40-41 y leg. 1901, exp. 12520. 
proveyera mientras el rey no cambiase de parecer al respecto. Nuevamente sólo se presentó un fraile franciscano, Luis Ibáñez, quien obtuvo la propiedad de la cátedra. ${ }^{21}$ Cabe mencionar el interés de los franciscanos en la lectura de la cátedra, ya que la Orden contaba con doctrinas en la zona cakchiquel.

El gran terremoto que sacudió a Guatemala en 1773, destruyendo la catedral y varios edificios de la hoy llamada Antigua, fue la causa por la que las autoridades reales impulsaron el traslado de la ciudad. A consecuencia de ello las escuelas de la Universidad, ${ }^{22}$ uno de los pocos edificios que no se vieron seriamente dañados, fueron el refugio de las pinturas y algunos otros objetos que se sacaron de la catedral. Lo anterior trastocó el funcionamiento de la Universidad, y el Claustro tuvo que sesionar en distintos lugares: primero, en el rancho del hospital de San Pedro; luego, en una sala provisional dentro del Seminario Tridentino; después, la Orden dominica ofreció a la Universidad trasladarse al rancho de su convento en Santiago de los Caballeros de Guatemala, como lo hizo. ${ }^{23}$ La máxima autoridad de la Capitanía solicitó un informe sobre la hacienda de la Universidad, y el Claustro aprovechó para señalar que había propuesto solicitar al rey que la cátedra de Lengua Cakchiquel, que había quedado vacante por muerte de su titular, se sustituyera por una de vísperas de Medicina. Mientras se resolvía su petición, dicho Claustro había acordado que el salario de la cátedra, 200 pesos, se sumara a 249 pesos sobrantes para la construcción de un edificio en la nueva sede de la ciudad. El Claustro pugnaba por fortalecer a la facultad médica que sólo contaba con la cátedra de prima, y propuso crear una de vísperas, notoria decisión, sobre todo porque ni la matrícula ni la concesión de grados en medicina eran muy significativas respecto a otras facultades, como la de artes o incluso la de cánones. También se refirió la orden real de enseñar castellano a los indígenas para que "[...] a más de adquirir más perfecta instrucción en los misterios de nuestra religión, se civilicen [...]". ${ }^{24}$

El Claustro apuntó que pocos acudían a la cátedra de lengua, en la cual, por otra parte, sólo aprendían algunos rudimentos, añadiendo que el idioma se perfeccionaba con la práctica. También se explicó que, por la variedad de lenguas, la cátedra no era útil para los curas que eran nombrados en otras zonas, donde los idiomas los aprendían con la convivencia. Aunque la cátedra no se suprimió, quedó vacante los siguientes años. Mientras tanto, la Universidad se había trasladado a la Nueva Guatemala de la Asunción. Su Claustro inició las sesiones en

${ }^{21}$ AGCA, A1.3, leg. 1890, exp. 12338, ff. 91-92.

22 En esta época la universidad era el gremio, mientras que al edificio de la institución se le conocía como "las escuelas".

${ }^{23}$ El 27 de marzo de 1773 fue la última vez que el claustro de la Universidad se reunió en su edificio: a partir de noviembre de ese año se encontraba sesionando fuera de las escuelas. El Libro de claustros registró cada uno de los lugares en los que se reunió éste: en 1774 la Orden de Predicadores ofreció un patio, que aceptó el claustro, trasladando las bancas, las cátedras y lo necesario para celebrar sus juntas. De esta manera, la Universidad volvía a su recinto original, el convento de Santo Domingo. Hacia 1777, el claustro sesionaba en una habitación del rancho del doctor Miguel de Montúfar, deán de la catedral. AGCA, A1.3, leg. 1890, exp. 12338, ff. 121v-122.

${ }^{24}$ AGCA, A1.3, leg. 1890, exp. 12338, ff. 102-104. 
la nueva sede el cinco de noviembre de 1777 , pero en una sala provisional del convento de San Agustín. ${ }^{25}$

Un año después del traslado de la Universidad se reanudó la discusión acerca de la utilidad de la cátedra de lengua cakchiquel. En el Claustro pleno del tres de abril de 1778 los doctores plantearon que la institución no contaba con los recursos necesarios para lectura de las cátedras que ya existían, pero también aseguró que era necesario crear las de Anatomía, Química, Cirugía, Botánica, Sagrada Escritura, Decreto, Código, Matemáticas y Retórica. Así, los doctores llegaron al acuerdo de la "inutilidad" de la cátedra de Lengua Cakchiquel y acordaron solicitar al monarca la supresión definitiva de su lectura, asignando los 200 pesos anuales de salario al rector, para que éste pudiera cubrir parte de los gastos de la construcción de las escuelas. ${ }^{26}$

De la cátedra de Cakchiquel no se volvería a tratar hasta que se presentó un problema mayor: la reforma del método de estudios. A principios de la década de los ochenta del siglo xvil, el fraile dominico Fermín de Aleas había enviado una petición al rey para que se revisara y modificara el método de estudios. El soberano respondió con una cédula real en la que pidió a la Universidad que se le informara sobre el asunto. Los miembros del Claustro, molestos por la acción del fraile a quien habían concedido la borla doctoral sin pago de derechos, enviaron el informe y arremetieron contra el dominico. ${ }^{27}$ Sin embargo, el Claustro pleno aprovechó para hacer las modificaciones que desde hacía tiempo había expresado, entre ellas la supresión de la cátedra de Lengua Cakchiquel, misma que se llevó a efecto el 23 de enero de $1783 .^{28}$

El proceso de reforma concluyó el 29 de enero de 1787 cuando, una vez realizadas la propuesta y gestiones necesarias, el rey envió su cédula en que ordenaba de manera concreta qué debía leerse en cada facultad y cátedra. Para las cátedras sin facultad, como la de Lengua Cakchiquel, el monarca ordenó que ésta debía restablecerse, no en la Universidad, sino en el Seminario Conciliar, y decidió que su lector sería el mismo que había sido nombrado cuando la cátedra aún se leía en la Universidad, además de que su salario saldría de las arcas universitarias. ${ }^{29}$

Al parecer, ni esta decisión, ni el hecho de que no se admitiera la propuesta de sustituirla por una de vísperas de medicina, o que la cátedra cambiara la sede de su lectura, y mucho menos que las rentas para la lectura de lengua cakchiquel

\footnotetext{
25 Ibid., ff. 121v-122. Cabe señalar que la Universidad fue una de las últimas instituciones en trasladarse a la nueva ciudad: insistió en permanecer en la Antigua Guatemala, pero las autoridades presionaron. De ahí que cuando se trasladó, su edificio aún estuviera en construcción.

${ }^{26}$ AGCA, A1.3, leg. 1890, exp. 12338, ff. 125-127.

27 Adriana Álvarez Sánchez, 2011, “Debate y reforma del método de estudios en la Real Universidad de San Carlos de Guatemala del siglo xvı", Revista Iberoamericana de Educación Superior (RIES), II, (5): 82-99. México: Instituto de Investigaciones sobre la Universidad y la Educación, Universidad Nacional Autónoma de México.

${ }^{28}$ AGCA, A1.3, leg. 1890, exp. 12338, ff. 167-168v.

29 AGCA, A1.3, leg. 1882, exp. 12236, ff. 150-158. También en John Tate Lanning, op. cit., pp. 208-216.
} 
dependieran sólo de la Universidad, causaron conflicto alguno en el seno de ésta. ${ }^{30}$

El catedrático que, en teoría, se encontraba leyendo la cátedra había muerto hacia 1774 , por lo que la silla estuvo vacante desde entonces. No obstante, los edictos convocatorios se publicaron el seis de julio de 1789. Al concurso acudieron dos aspirantes, ambos presbíteros seculares, situación que no se había dado desde los años treinta. La cátedra se adjudicó, con tres de los cinco votos, al bachiller José Gregorio Marroquín, con lo cual el perfil del regente cambió, ya que los últimos tres catedráticos habían sido frailes franciscanos. Este hecho estuvo relacionado con el cambio de sede de la lectura de la cátedra, pues una vez que la cátedra pasó al Seminario Conciliar, los catedráticos pertenecieron al clero secular. Sin embargo, el problema de la lectura de la cátedra no se resolvió, pues meses después el catedrático solicitó al Claustro pleno: "[...] se le franque claze en esta Universidad por su lectura, por no haver pieza en el Seminario donde se lea como está mandado [...]".31

En 1803, el catedrático Marroquín enfermó y el Claustro de consiliarios planteó la posibilidad de nombrar a un sustituto, decisión que quedó en manos del rector. Éste emprendió la labor de demostrar la inutilidad de la cátedra.

No obstante, a la muerte de Marroquín, 15 años después de haber sido nombrado catedrático, se convocó a concurso de oposición para la cátedra de Lengua Cakchiquel. En 1804 asistieron cuatro aspirantes. Lo interesante de este caso no sólo se debe al hecho de que hubiera, por primera vez, cuatro concursantes, sino también a las características de éstos. Entre los aspirantes se encontraban dos indígenas: el primero de ellos, José Francisco González, indio cacique nacido en el pueblo de San Pedro de la Laguna y avecindado en el de Texar, declaró ser "materno en dicho idioma $4 a$ akhiquel, quiché, połoman y pupulu $4 a$ ", 32 lenguas en las que había servido como examinador sinodal; el otro era el bachiller Antonio López, clérigo de menores órdenes y cursante de Cánones y Leyes en la Real Universidad de San Carlos, quien afirmó contar con las aptitudes necesarias para ser maestro del idioma cakchiquel y tzutuhil. De los otros dos, el primero, Juan José de Bárcena, sólo anotó ser vecino de la ciudad e idóneo para leer la cátedra, pues sabía cakchiquel, quiché y tzutuhil; el segundo fue fray Paulino Solano, franciscano, quien además afirmó ser catedrático de Filosofía, y aunque no precisa en qué convento, es posible que se refiriera al de la ciudad de Guatemala.

${ }^{30}$ AGCA, A1.3, leg. 1903, exp. 12553.

${ }^{31}$ Claustro del 26 de abril de 1790. AGCA, A1.3, leg. 1891, exp. 12339, f. 138 y leg. 1890, exp. 12338 , ff. $280 \mathrm{v}-281$.

32 Las lenguas a las que se refiere el concursante José Francisco González son kaqchikel, k'iché', poqoman, que se hablaban (y hablan) en el occidente de Guatemala, y el popoluca, idioma de la familia otomangue. 
Después de los actos académicos correspondientes, la cátedra se adjudicó a Antonio López, quien, además de ser indio y clérigo, era bachiller y cursaba las facultades de Derecho, es decir, Cánones y Leyes. ${ }^{33}$

Como se puede observar, la Orden de San Francisco no había quitado el dedo del renglón de hacer mayor presencia en la Universidad a través de sus expertos en lenguas indias, pero los clérigos habían hecho lo propio. En 1810, el catedrático presentó ante el Claustro pleno su renuncia a la cátedra, debido al inicio de un proceso en su contra, acusado de no leer su cátedra, no tener estudiantes y ser un borracho. ${ }^{34}$ Los testimonios del expediente conservado en el archivo universitario son una rica fuente de información, no sólo acerca del mal funcionamiento de la cátedra y del casi nulo número de estudiantes, sino también del comportamiento de un individuo que vivía en el convento franciscano y que, según el rector del Seminario, sólo aprovechaba el salario de la cátedra, haciéndola "inútil al pueblo y solo probechosa al catedrático". Más importantes aún son las referencias al método de enseñanza de la lengua dentro de la Universidad, un tema que requiere de un amplio estudio. ${ }^{35}$

El episodio de la renuncia del bachiller López concluyó con la solicitud de éste de ser nombrado bibliotecario de la Universidad, a fin de defenderse de la acusación de alcoholismo. El caso quedó pendiente, pero reabrió la discusión acerca de la utilidad de la enseñanza del cakchiquel en la Universidad y sumó argumentos a sus detractores. ${ }^{36}$

\section{La (in)utilidad de la cátedra de Lengua y su desaparición en el siglo XIX}

Ante la solicitud de renuncia del catedrático bachiller Antonio López, los integrantes del Claustro pleno votaron para decidir qué harían si la cátedra quedaba vacante, pues no aceptaron de inmediato la renuncia del regente. Por un lado, hubo quienes afirmaban que el rector, el doctor Juan José Batres, debía proceder a declarar vacante la cátedra, propuesta que obtuvo ocho de los 15 votos; por otro, estaban quienes creían que era necesario que el rector suspendiera al catedrático. Seis de los doctores votaron por esta opción. El restante opinó que antes de decidir debía hacerse una investigación y conformar un expediente sobre el caso.

${ }^{33}$ Claustro pleno del 19 de noviembre de 1814. AGCA, A1.3, leg. 1904, exp. 12589.

${ }^{34}$ Ibid.

${ }^{35} \mathrm{Al}$ respecto, hemos avanzado en la investigación acerca del proceso de normalización de las lenguas indígenas y de su enseñanza, centrándonos en el caso del cakchiquel, bajo la premisa de que éste fue un proceso de traducción cultural. Actualmente preparamos un libro sobre el tema, aunque ya se han presentado algunos avances en el Coloquio de Estudios Modernos, México, Facultad de Filosofía y Letras, Universidad Nacional Autónoma de México, septiembre de 2013, y en el XI Congreso Centroamericano de Historia, San Salvador, julio de 2014.

${ }^{36}$ AGCA, A1.3, leg. 1892, exp. 12340, ff. 17v-18. 
En el contexto americano había una preocupación por la representación de estos territorios ante el Consejo de Regencia, creado a raíz de la captura del rey por parte de los franceses. No obstante, la vida universitaria guatemalteca siguió su curso: se eligió al rector anualmente, se atendieron las vacantes de las cátedras, se revisaron las cuentas, etcétera. ${ }^{37}$

Será hasta el 21 de agosto de 1812 cuando el Claustro de consiliarios vuelva a tratar el tema de la cátedra y acepte la renuncia de Antonio López, declarando vacante la cátedra, pero "[...] reservándose el proceder a su provición para mejor oportunidad [...]". Apenas un mes después el Claustro estaba jurando la Constitución Política de la Monarquía Española. ${ }^{38}$

Para noviembre de ese mismo año, en el Claustro de consiliarios se presentó una consulta del síndico de la Universidad en que preguntaba si debía pagar o no el salario al catedrático de Lengua, pero el caso se turnó al Claustro pleno. ${ }^{39}$ Lo anterior muestra que en el seno del órgano que debía decidir las cuestiones hacendarias no hubo acuerdo acerca del pago del salario del catedrático de Lengua, quizá con el objetivo de suprimirla. Un mes después, el rector, doctor Diego José Batres, ordenó formar un expediente sobre el desarrollo de la cátedra en las dos últimas décadas para decidir sobre su utilidad o inutilidad.

El documento está constituido por una serie de cinco testimonios, registrados entre 1812 y 1813 , sobre la cátedra, sus lectores, sus estudiantes y el provecho de ésta. Cabe señalar que tres de los testigos eran clérigos, otro era un maestro y el último era el propio secretario de la Universidad. Todos declararon la inutilidad de la cátedra para aprender el idioma cakchiquel y afirmaron que éste sólo se aprendía con la práctica. ${ }^{40} \mathrm{~A}$ pesar de que ni los estatutos ${ }^{41}$ ni los expedientes de las oposiciones refieren el método utilizado para la enseñanza de la lengua, los testimonios mencionados permiten inferir que en la cátedra se ofrecían los elementos teóricos.

\footnotetext{
${ }^{37}$ Adriana Álvarez Sánchez, 2010, "La Real Universidad de San Carlos de Guatemala ante el proceso de Independencia (1808-1815)”, 200 años de Iberoamérica (1810-2010). Congreso Internacional, pp. 489-508, Eduardo Rey Tristán y Patricia Calvo González (eds.). Santiago de Compostela: Universidad de Santiago de Compostela.

${ }^{38}$ AGCA, A1.3, leg. 1892, exp. 12340, f. 26v. La Constitución se juró hasta el 26 de septiembre. Su registro se encuentra en el mismo legajo y expediente, en los folios $27 \mathrm{v}-28$.

${ }^{39}$ AGCA, A1.3, leg. 1892, exp. 12340, f. 29.

${ }^{40}$ AGCA, A1.3, leg. 1905, exp. 12605.

${ }^{41}$ En un inicio la Universidad de San Carlos utilizó los estatutos de la Real Universidad de México, redactados por el arzobispo Juan de Palafox y Mendoza en el siglo xvI. Sin embargo, en 1681 el superintendente de la Universidad guatemalteca Francisco de Sarasa y Arce redactó la primera versión, con base en la legislación mexicana, de inspiración salmantina. El cuerpo estatutario de Guatemala fue aprobado en 1686, previa revisión del Consejo de Indias, lugar en el que se las reformó. Entre los cambios más importantes se encuentra la prohibición a oidores, alcaldes de corte, fiscales de la Audiencia, inquisidores y fiscales de la Inquisición de incorporarse a la Universidad. En 1976 la Universidad de San Carlos publicó en edición facsimilar el manuscrito de 1681 y la reimpresión de 1783 de los estatutos publicados originalmente en 1686. Ésta es la edición que se utiliza en el presente artículo. Véase Francisco de Sarasa y Arce, 1976 [1681 y 1686], Estatvtos y Contitvciones Reales de la Regia Vniversidad de San Carlos de Goathemala, edición facsimilar. Guatemala: Editorial Universitaria (Tricentenario de la Universidad de San Carlos).
} 
Es posible que los catedráticos siguieran alguna gramática, pero aún no podemos afirmarlo. Sería interesante saber si, como en el caso del náhuatl, el cakchiquel se hubiera convertido en la lengua base para realizar las gramáticas de otras lenguas del reino. Habrá que continuar investigando el desarrollo comparado de la cátedra de cakchiquel y de la producción de estudios filológicos en la propia época virreinal para despejar dichas incógnitas y reconstruir parte del pasado lingüístico centroamericano y novohispano.

En su sesión del 11 de enero de 1813 el Claustro pleno afirmó haber probado la "positiva inutilidad" de la cátedra en la que se habían gastado miles de pesos sin provecho. Se ordenó enviar el informe a la Regencia del Reino, junto con los testimonios. La documentación también fue enviada a la Real Audiencia, quien en 16 de agosto de 1816 determinó no proveer la cátedra hasta consultar directamente a la Regencia. En España no se atendió el caso hasta 1819, cuando el rey —restituido a su trono- envió una cédula al presidente de la Audiencia y vicepatrono de la Universidad. ${ }^{42}$ El Claustro recibió la orden real, pero no resolvió el asunto inmediatamente, dejando la decisión rezagada y resolviéndola hasta $1826 .{ }^{43}$

Las razones por las que el asunto concreto se dejó de lado están relacionadas con una nueva reforma del plan de estudios general, cuya discusión se llevó a cabo entre 1820 y 1821 . Se comisionó a los doctores Rojas, Gálvez, Escoto, Medina y al bachiller Solís para revisar un plan de estudios ya redactado y planear la manera en que éste se podía aplicar. ${ }^{44}$

Otra de las razones fue la jura de la Independencia de Guatemala, "como está prevenida en la acta celebrada en el palacio nacional de esta ciudad". ${ }^{45}$ Además, la Universidad preparó una serie de funciones para celebrar la conformación de Guatemala como nación independiente. Sin embargo, un año después, el 7 de marzo de 1822, la Universidad recibió un pliego con el juramento de unión de Guatemala al Imperio mexicano. La jura se llevó a cabo más de un mes después, el 10 de abril de dicho año, pero parece necesario señalar que el Claustro cuestionó si debía jurar o no el documento tal y como estaba redactado. ${ }^{46}$ La Universidad, atendiendo a la tradición del Antiguo Régimen, continuaba rindiendo lealtad al rey y reconociéndolo como patrono, pues incluso seguía manteniendo la organización de su gobierno, basada en el modelo salmantino y mexicano. ${ }^{47}$

${ }^{42}$ AGCA, A1.3, leg. 1905, exp. 12615, ff. 3-3v. Consúltese John Tate Lanning, op. cit., pp. 310-311.

43 AGCA, A1.3, leg. 1892, exp. 12340, f. 100v.

44 Ibid., f. 122.

45 Ibid., ff. 128-129v.

46 AGCA, A1. leg. 1892, exp. 12340, ff. 136v-140.

${ }^{47}$ El modelo que se utilizó para fundar las universidades reales americanas fue el salmantino, donde el rector era la "cabeza" de la universidad; el maestrescuela, en el caso americano, únicamente se ocuparía de asuntos protocolarios, a diferencia del mismo cargo en España, donde tenía jurisdicción sobre los universitarios. Ésta sería una de las limitaciones que la Corona impuso al Estudio General en América. Sin embargo, los distintos tipos de claustros eran los órganos de gobierno, en cuyas reuniones se tomaban las decisiones relativas al funcionamiento interno y también se 
Así, fue hasta el 28 de febrero de 1826 cuando se volvió a hablar de la cátedra de lengua, aunque en esta ocasión el Claustro consideró más apropiado denominarla "aborigen". Según el acta de esa reunión, las rentas de las cátedras aborígenes, incluyendo la de pipil, se usaron para pagar el salario del catedrático de la de Química. Se propuso asimismo que las propinas de los grados mayores y menores también se sumaran al caudal para pagar el salario del lector de Química. ${ }^{48}$ Con esta decisión conseguiría por fin el Claustro suprimir la cátedra de cakchiquel que, a pesar de todo, sobrevivió por más de un siglo.

Las universidades habían sido los centros de formación de la burocracia y como tales, impartieron conocimientos en las distintas ramas del saber, que contribuyeron a administrar los territorios de la monarquía. Entre las disciplinas que se enseñaron estaban las lenguas locales, cuyo conocimiento permitiría, en teoría, evangelizar a los indígenas. Sin embargo, la cambiante política linguística, la variedad y complejidad de las lenguas y las tensas relaciones entre los distintos poderes públicos tanto americanos como peninsulares, hicieron de la enseñanza y el estudio de los idiomas una historia de rupturas y continuidades, pero todo ello en gran medida se quedó en el ámbito de lo teórico. Otras serían las lenguas habladas, cuyo desarrollo también deberá estudiarse. Pero la enseñanza de las lenguas indígenas desapareció con la creación de la nueva nación.

\section{Consideraciones finales}

La historia de las cátedras de Lenguas Indígenas es una muestra del desarrollo mismo de la Universidad pública de Guatemala. Las sillas eran espacios académicos e ideológicos pero también de poder político, ya que la intención de fundar estas cátedras era la de controlar la asignación de los cargos en la burocracia, cargos que en la segunda mitad del siglo xvIII fueron limitados para los nacidos

\footnotetext{
establecían las relaciones de la Universidad con otras corporaciones e instituciones. En San Carlos hubo tres tipos de claustros: el de consiliarios, que elegía al rector, a sus sucesores y se ocupaba de declarar vacantes las cátedras; el de diputados de hacienda, que, como su nombre indica, se encargaba de los asuntos económicos, y el claustro pleno que era el máximo órgano de gobierno, mismo en que se trataban el resto de los asuntos y todos aquellos que no pudiesen resolverse en el seno de los dos anteriores. Además, en los libros de las actas de estos claustros, se registraron las sesiones de la Junta de votación, conformada por autoridades reales y universitarias, y encargada de elegir a los catedráticos. Acerca del modelo claustral y de otros modelos de instituciones, puede verse Mariano Peset Reig, 1993, "La organización de las universidades españolas en la edad moderna”, Studi e derrito nell'area mediterránea in età moderna, pp. 73-122, Andrea Romano (coord.). Italia: Rubbettino. Mariano Peset Reig y Pilar García Trobat, 2002, "Poderes y modelos universitarios, siglos XVI-xIx", Historia de la Universidad de Salamanca, pp. 37-91. Salamanca: Universidad de Salamanca. Acerca de los tipos de claustros salmantinos, véase Luis Enrique Rodríguez San-Pedro, 1986, La Universidad Salmantina del Barroco. Valencia: Universitat de València y Caja de Ahorros y Monte de Piedad, 3 vols.

${ }^{48}$ AGCA, A1.3, leg. 1892, exp. 12340, ff. 174v-175v.
} 
en América. ${ }^{49}$ Por ello, las distintas corporaciones buscaron tener presencia en una institución que implicaba prestigio social.

En la Universidad Carolina, desde sus inicios, es evidente la presencia de la Corona a través de sus ministros: la organización, los preparativos y más adelante, su funcionamiento, estuvieron determinados por individuos que, además de ser catedráticos, rectores y doctores, pertenecían el clero secular. Por su parte, los frailes de las distintas órdenes también lograron contar con espacios en las cátedras - no así en los cargos de gobierno, como el de rector, pues la legislación lo prohibía—, ${ }^{50}$ desde donde difundían las distintas corrientes teológicas y filosóficas, siempre en pugna.

Sin embargo, no todas las facultades y cátedras tenían la misma importancia dentro de la Universidad. Sin duda, Teología y Cánones fueron los saberes más apreciados, en tanto que las cátedras de Lenguas, aunque necesarias, no pertenecían a ninguna facultad, no tuvieron estudiantes y, por los testimonios que se conservan, la opinión de los órganos de gobierno hacia su enseñanza casi siempre fue negativa. Los intentos por probar la inutilidad de la cátedra por parte del Claustro y algunos de los rectores, en combinación con la falta de cursantes, hizo de ésta un espacio de enseñanza casi ficticio. No obstante, habría que preguntarse por qué, a pesar de ello, la cátedra de cakchiquel sobrevivió hasta 1826. La respuesta es que la silla, al igual que las de otras cátedras, fue un espacio de poder: la mayor parte de los lectores que no murieron en funciones, ascendieron en la administración de la Iglesia, como sucedió a la par con los lectores de las cátedras de lenguas en México ${ }^{51}$ y de los catedráticos de las facultades de leyes y cánones en Guatemala. El estudio de la población de catedráticos universitarios, de su carrera académica y burocrática, así como las políticas respecto de las lenguas y la construcción del conocimiento linguiístico guatemalteco contribuirá a comprender de manera más profunda, no sólo el desarrollo de las cátedras de lenguas, sino también de la Universidad y del propio Reino.

\footnotetext{
${ }^{49}$ Aguirre Salvador explica que en la primera mitad del siglo los criollos pudieron acceder a cargos de la burocracia, en gran medida, gracias al despunte en la venta de los mismos por parte de la Corona. Sin embargo, en la segunda mitad de la centuria la restricción para los españoles americanos se centró en las sillas de las audiencias, política que también se aplicaría posteriormente a los nombramientos eclesiásticos. Hasta 1790 los criollos contaron con mayor número de nombramientos en la jerarquía del clero secular. Rodolfo Aguirre Salvador, 2003, El mérito y la estrategia. Clérigos, juristas y médicos en Nueva España, pp. 35-37. México: Centro de Estudios Superiores Universitarios y Plaza y Valdés.

${ }^{50}$ Véase Francisco de Sarasa y Arce, "Título II. De la elección de Rector y Consiliarios, constitución 9. Qué personas no pueden ser Rector”, op. cit.

${ }^{51}$ Sobre las cátedras de lenguas en México, consúltese Adriana Álvarez Sánchez, 2009, "La cátedra universitaria de lenguas indígenas en México. Siglos xvı y xvı", op. cit. Acerca de los catedráticos de la Universidad de San Carlos, la misma autora ha avanzado en el estudio sistemático de la población de catedráticos, en 2013, "Los catedráticos juristas de la Real Universidad de San Carlos de Guatemala (1678-1800)", Poderes y educación superior en el mundo hispánico. Siglos XV al XX, pp. 148-181, Mónica Hidalgo Pego y Rosalina Ríos Zúñiga (coords.). México: Instituto de Investigaciones sobre la Universidad y la Educación, Universidad Nacional Autónoma de México.
} 
En el contexto de los cambios internos del método de estudios hacia 1780, la cátedra fue abiertamente declarada inútil, pero el patrono de la Universidad no permitió la desaparición de la enseñanza de las lenguas, ${ }^{52}$ toda vez que, de alguna manera, seguía siendo un mecanismo de control en la asignación de curatos, pues oficialmente el catedrático debía certificar que todo aquél aspirante al sacerdocio conocía la lengua de su grey.

Más adelante, en los albores de la independencia, se registró otro cambio en el plan de estudios, en que la cátedra de cakchiquel ya no figuraba como disciplina útil. El último de los catedráticos, José López, acusado de no cumplir con su cargo, también muestra un cambio en el discurso de quienes hasta entonces habían leído la cátedra y que quizá sea representativo del rumbo que tomarían las iniciativas independentistas:

Porque a mi antecesor el padre don José Marroquin es constan[te] que no tubo discípulos, no se le quito la catedra, ni al maestro reverendo padre doctor y maestro fray Juan José Terraza que tampoco tenía discípulos? Porque estos eran sacerdotes ancianos y eran españoles, me dirán. A mi si se me debe quitar porque soi yndio y no soi de las condiciones expresadas. Pero yo digo que así conviene a los pobres indios que no sean felices que sean siempre oprimidos por los de aquí $[\ldots]^{53}$

Ante la restricción de la Corona para que los americanos ocuparan cargos públicos - tanto civiles como eclesiásticos-, este catedrático empleó en su favor el argumento de la diferencia respecto de sus antecesores, quienes tampoco tuvieron cursantes, pero que eran españoles. Sin embargo, no explicó que se trataba de españoles americanos, es decir, de criollos para los que hacía tiempo también se habían cerrado las puertas del ascenso burocrático y social. José López aún pugnaba por permanecer en la cátedra, misma que, finalmente, tenía un salario y, aunque menor que el otorgado a los regentes de teología o cánones, la cátedra garantizaba cierto prestigio social.

Se crearon nuevas cátedras que sustituyeron a las de lenguas. Pero ello no significó un cambio radical en los saberes, pues una de las sillas fundada fue la de retórica, disciplina de tradición medieval necesaria para ingresar a la Universidad. Habría que estudiar el lugar y la utilidad del latín en lo que parecía una nueva etapa en la historia del Estudio general, lo que requiere de una investigación distinta. Por ahora nos hemos centrado en la reconstrucción y análisis del desarrollo de la enseñanza de las lenguas indígenas en la Real Universidad de San Carlos, donde sólo sobrevivió la de cakchiquel durante todo el periodo colonial.

\footnotetext{
${ }^{52}$ La cédula real por la que el rey, como patrono de la Universidad, ordenó al Claustro y al rector que la cátedra se mantuviera, data del 29 de enero de 1787. AGCA, A1.3, leg. 1882, exp. 12282, ff. 150-158. El mismo Lanning (op. cit., pp. 208-216) menciona que el rey envió, con algunos cambios, copia de la cédula al presidente de la Audiencia, quien fungía, en su representación, como vicepatrono. AGCA, A1.3, leg. 1532, exp. 10087, ff. 12-20, y registra otra copia en leg. 2378, exp. 18025.

53 AGCA, A1.3, leg. 1957, exp. 13158.
} 


\section{BIBLIOGRAFÍA}

Aguirre Salvador, Rodolfo

2003 El mérito y la estrategia. Clérigos, juristas y médicos en Nueva España. México:

Centro de Estudios Superiores Universitarios y Plaza y Valdés.

Álvarez Sánchez, Adriana

2007 "La Real Universidad de San Carlos de Guatemala. 1676-1790", tese de doutoramento en Historia. Santiago de Compostela: Universidad de Santiago de Compostela, Facultade de Xeografía e Historia.

2009 "La cátedra universitaria de lenguas indígenas en México. Siglos xvı y xvı", De la barbarie al orgullo nacional. Indígenas, diversidad cultural y excusión. Siglos XVI al XIX, pp. 153-187, Miguel Soto y Mónica Hidalgo (coords.). México: Universidad Nacional Autónoma de México.

2010 "La Real Universidad de San Carlos de Guatemala ante el proceso de Independencia (1808-1815)", 200 años de Iberoamérica (1810-2010). Congreso Internacional, pp. 489-508, Eduardo Rey Tristán y Patricia Calvo González (eds.). Santiago de Compostela, España: Universidad de Santiago de Compostela (Cursos y Congresos, 196).

2011 "Debate y reforma del método de estudios en la Real Universidad de San Carlos de Guatemala del siglo xvin”, Revista Iberoamericana de Educación Superior (RIES), II (5): 82-99. México: Instituto de Investigaciones sobre la Universidad y la Educación, Universidad Nacional Autónoma de México, disponible en <http://ries.universia.net/index.php/ries/article/view/74>.

2013 "Los catedráticos juristas de la Real Universidad de San Carlos de Guatemala (1678-1800)", Poderes y educación superior en el mundo hispánico. Siglos xV al XX, pp. 148-181, Mónica Hidalgo Pego y Rosalina Ríos Zúñiga (coords.). México: Universidad Nacional Autónoma de México, Instituto de Investigaciones sobre la Universidad y la Educación.

s. f. Patronazgo y educación. Los proyectos y la fundación de la Real Universidad de San Calos de Guatemala, 1619-1687. México: Universidad Nacional Autónoma de México, Facultad de Filosofía y Letras, en prensa.

Anderson, Perry

1979 El Estado absolutista, trad. de Santos Juliá. México: Siglo XXI Editores (Historia).

González González, Enrique

2010 "Por una historia de las universidades hispánicas en el Nuevo Mundo (siglos XVI-XVIII)", Revista Iberoamericana de Educación Superior (RIES), 1, (1): 77-101. México: Instituto de Investigaciones sobre la Universidad y la Educación, Universidad Nacional autónoma de México, disponible en < http://ries.universia. net.mx/index.php/ries/article/view/29> (consulta: 15 de noviembre de 2014).

Jickling, David

1985 "The Vecinos of Santiago de Guatemala in 1604", Estudios del Reino de Guatemala. Homenaje al profesor S. D. Markman, pp. 77-100. Sevilla: Duke University, Escuela de Estudios Hispanoamericanos y Consejo Superior de Investigaciones Científicas. 
Lanning, John Tate

1976 Reales cédulas de la Real y Pontificia Universidad de San Carlos, 2a ed. Guatemala: Editorial Universitaria (Tricentenario de la Universidad de San Carlos de Guatemala).

Lovell, George W. y Christopher H. Lutz

2000 Demografía e Imperio. Guía para la historia de la población de la América Central Española, 1500-1821. Guatemala: Plumsock Mesoamerican Studies y Editorial Universitaria de la Universidad de San Carlos de Guatemala (Colección Monografías).

Matthew, Laura y Sergio Romero

2014 "El pipil en la Guatemala colonial: unas propuestas", ponencia presentada en el XII Congreso Centroamericano de Historia, San Salvador, El Salvador, del 14 al 18 de julio.

Peset Reig, Mariano

1993 "La organización de las universidades españolas en la edad moderna", Studi e derrito nell'area mediterránea in età moderna, pp. 73-122, Andrea Romano (coord.). Milán: Rubbettino.

Peset Reig, Mariano y Pilar García Trobat

2002 "Poderes y modelos universitarios, siglos XVI-XIX", Historia de la Universidad de Salamanca, pp. 37-91. Salamanca: Universidad de Salamanca.

Ramírez González, Clara Inés

2001 Grupos de poder clerical en las universidades hispánicas. Los regulares en Salamanca y México durante el siglo XVI. México: Universidad Nacional Autónoma de México, Centro de Estudios Sobre la Universidad, 2 vols. (La Real Universidad de México. Estudios y Textos XII y XIII).

Ramírez González, Clara Inés y Mónica Hidalgo Pego

2001 "Los saberes universitarios", La Universidad de México. Un recorrido histórico de la época colonial al presente, pp. 70-86, Renate Marsiske (coord.). México: Universidad Nacional Autónoma de México, Centro de Estudios Sobre la Universidad y Plaza y Valdés Editores.

Rodríguez Cabal, Juan

1965 "Don fray Payo de Ribera y la Universidad de Guatemala”, Missionalia Hispánica, XII, (66): 17-54.

1966 "Parecer del ilustrísimo señor don fray Payo Enríquez de Ribera, obispo de Guatemala", Anales de la Sociedad de Geografía e Historia de Guatemala, XXXIX (1-4): 36-75.

Rodríguez San-Pedro, Luis Enrique

1986 La Universidad Salmantina del Barroco. Valencia: Universitat de València y Caja de Ahorros y Monte de Piedad, 3 vols. 
Sarasa y Arce, Francisco de

1686 Estatvtos y Contitvciones Reales de la Regia Vniversidad de San Carlos de Goathe-

[1976] mala, edición facsimilar a cargo de Manuel José Arce, Augusto Cazali Ávila y Francisco Albizúrrez. Guatemala: Editorial Universitaria (Tricentenario de la Universidad de San Carlos).

Ximénez, Francisco

1993 Historia de la Provincia de San Vicente de Chiapa y Guatemala de la Orden de Predicadores. Chiapas: Consejo Estatal para la Cultura y las Artes, 5 t.

Documentos inéditos

Archivo General de Centro América (AGCA)

A1.3, leg. 1882, exp. 12235. Real cédula de fundación de la Real Universidad de San Carlos de Guatemala, 31 de enero, 1676.

A1.3, leg. 1882. Reales cédulas de la Universidad, 1756.

A1.3, leg. 1890. Testimonios de actas de claustros y Libro $2^{\circ}$ de actas de claustros, 1656-1790.

A1.3, leg. 1891, libro $3^{\circ}$ de actas de Claustro, 1790-1808.

A1.3, leg. 1892, libro $4^{\circ}$ de actas de Claustros, 1808-1831.

A1.3, leg. 1899, expedientes de provisiones de cátedras, 1697-1726.

A1.3, leg. 1900, expedientes de provisiones de cátedras, 1726-1746.

A1.3, leg. 1901, expedientes de provisiones de cátedras, 1751-1767.

A1.3, leg. 1903, expedientes de provisiones de cátedras, 1789-1796.

A1.3, leg. 1904, expedientes de provisiones de cátedras, 1797-1805.

A1.3, leg. 1905, expedientes de provisiones de cátedras, 1806-1821.

A1.3, leg. 1957, exp. 12158. Causa contra Antonio López, 1810.

Archivo General de Indias (AGI)

Audiencia de Guatemala, 373, ff. 88-116v. Parecer del ilustrísimo señor don fray Payo Enríquez de Ribera, obispo de Guatemala, 17 de octubre de 1659. 